\title{
Improving Analysis of Infrared Spectra of van der Waals Complex with Theoretical Calculation: Applied to $\mathrm{Xe}-\mathrm{N}_{2} \mathrm{O}$ complex
}

\author{
Lipeng Shi ${ }^{1}$, Aiqing Zhao ${ }^{1}$, Hongli Wang ${ }^{1}$, Dapeng Yang ${ }^{1}$, Rui Zheng ${ }^{1}$
}

1、School of Mathematics and Information Science, North China University of Water Resources and Electric Power, Zhengzhou 450011, China

* Corresponding author: Dr. Rui Zheng

School of Mathematics \& Information Science North China University of Water Resources and Electric Power

Beihuan Road 36, Zhengzhou 450011

China

E-mail: zhengrui@.ncwu.edu.cn

Tel: +8637169310027 


\title{
Improving Analysis of Infrared Spectra of van der Waals Complex with
}

\section{Theoretical Calculation: Applied to $\mathrm{Xe}-\mathrm{N}_{2} \mathrm{O}$ complex}

\begin{abstract}
:
A section of infrared spectrum for $\mathrm{Xe}-\mathrm{N}_{2} \mathrm{O}$ has been recorded in the $\mathrm{N}_{2} \mathrm{O}$ monomer $v_{1}$ region, but just 5 rotational resolved lines can not make an effective rovibrational analysis. To improve the analysis of our observed spectrum for $\mathrm{Xe}-\mathrm{N}_{2} \mathrm{O}$, a new method is developed based on the bound state calculations with three ab initio potential energy surfaces (PESs). The accuracy of this method is validated by the excellent agreement between theoretical and experimental results for 152 rovibrational transition frequencies with a root mean square deviation of $0.00075 \mathrm{~cm}^{-1}$ and spectroscopic parameters with the deviation less than $0.6 \mathrm{MHz}$ in the $\mathrm{N}_{2} \mathrm{O}$ monomer $v_{3}$ region. The rotational constants for the excited state are derived with the values of $\mathrm{A}=12716.1, \mathrm{~B}=$ 1075.2, $\mathrm{C}=987.9 \mathrm{MHz}$ in the $v_{1}$ region of $\mathrm{N}_{2} \mathrm{O}$ monomer. The band origin of the spectrum is determined to be $1284.8760 \mathrm{~cm}^{-1}$ with a red shift of $0.0273 \mathrm{~cm}^{-1}$ compared with that of $\mathrm{N}_{2} \mathrm{O}$ monomer in the $v_{1}$ region. The excellent agreement between experimental and theoretical results confirms that this new method is extremely helpful to make a rovibrational analysis for the infrared spectrum of van der Waals complex.
\end{abstract}

Keywords : Van der Waals Complex; Infrared Spectrum; Xe- $\mathrm{N}_{2} \mathrm{O}$; Potential energy surface; Bound sate calculations

\section{Introduction}

Due to the great atmospheric interest of nitrous oxide [1], vdW complexes involving $\mathrm{N}_{2} \mathrm{O}$ have drawn forth great interest and much research [2]. $\mathrm{Rg}-\mathrm{N}_{2} \mathrm{O}(\mathrm{Rg}=\mathrm{He}, \mathrm{Ne}, \mathrm{Ar}, \mathrm{Kr}, \mathrm{Xe})$ complexes are considered as the typical system to investigate intermolecular interaction and have been extensively investigated both experimentally [3-15] and theoretically [16-27]. $\mathrm{Ar}-\mathrm{N}_{2} \mathrm{O}$ is the first complex of this system, which has been widely experimentally studied using the microwave [3-5] and infrared [6-8] spectroscopic techniques. These spectroscopic results showed that the structure of $\mathrm{Ar}-\mathrm{N}_{2} \mathrm{O}$ complex is nearly T-shaped with the oxygen end of the $\mathrm{N}_{2} \mathrm{O}$ monomer slightly tilted towards the Ar atom. 
Now, the $\mathrm{Rg}-\mathrm{N}_{2} \mathrm{O}(\mathrm{Rg}=\mathrm{Ne}, \mathrm{Ar}, \mathrm{Kr}$ and $\mathrm{Xe})$ complexes have been well studied in the $v_{3}$ region of $\mathrm{N}_{2} \mathrm{O}$ monomer. The intermolecular distance (R) varies from 3.24 to $3.78 \AA$ and the angle $(\theta)$ between the intermolecular axis and the $\mathrm{N}-\mathrm{N}-\mathrm{O}$ axis varies from 82.0 to $84.6^{\circ}$. The vibrational shifts for $\mathrm{Rg}-\mathrm{N}_{2} \mathrm{O}(\mathrm{Rg}=\mathrm{Ne}, \mathrm{Ar}, \mathrm{Kr}$ and $\mathrm{Xe})$ were well explained based on the Buckingham intermolecular potential and this model can be also applied to the similar complexes of $\mathrm{Rg}-\mathrm{CO}_{2} / \mathrm{OCS}$ successfully [9]. Recently, the validity of this model was further confirmed by the results for $\mathrm{Rg}-\mathrm{N}_{2} \mathrm{O}(\mathrm{Rg}=\mathrm{Ne}, \mathrm{Ar}, \mathrm{Kr})$ in the $v_{1}$ region of $\mathrm{N}_{2} \mathrm{O}$ monomer [15].

In theory, the dynamics of $\mathrm{Rg}-\mathrm{N}_{2} \mathrm{O}(\mathrm{Rg}=\mathrm{Ne}, \mathrm{Ar}, \mathrm{Kr}$ and $\mathrm{Xe})$ have also been well established based on the high resolution intermolecular potential and bound state calculations [16-22]. The ab initio PESs give the intermolecular distance of 3.16, 3.47, 3.54 and $3.80 \AA$ for $\mathrm{Ne}^{-} \mathrm{N}_{2} \mathrm{O}$ [16], $\mathrm{Ar}-\mathrm{N}_{2} \mathrm{O}$ [17], $\mathrm{Kr}-\mathrm{N}_{2} \mathrm{O}$ [18] and $\mathrm{Xe}-\mathrm{N}_{2} \mathrm{O}$ [19], which are very close to their corresponding values of the effective distances determined by experiment. Since the infrared spectra of $\mathrm{He}-\mathrm{N}_{2} \mathrm{O}$ were investigated by Tang and McKellar [11], there have been several theoretical reports on this complex [23-27]. Good agreement has been achieved between the calculated spectra and the experimental results. The three-dimensional and four-dimensional ab initio PESs not only can be used to predict vibrational shifts accurately for ${ }^{4} \mathrm{He}-\mathrm{N}_{2} \mathrm{O}$ and ${ }^{3} \mathrm{He}-\mathrm{N}_{2} \mathrm{O}$, but also can be applied to study the dynamics of $\mathrm{He}_{\mathrm{N}}-\mathrm{N}_{2} \mathrm{O}$ cluster using the path integral Monte Carlo simulation [26, 27].

In this paper, we select $\mathrm{Xe}-\mathrm{N}_{2} \mathrm{O}$ complex as the object of theoretical and experiment studies. It attributes several factors: Firstly, the first PES was made for $\mathrm{Xe}-\mathrm{N}_{2} \mathrm{O}$ complex by Chen et al. [19] and the rovibrational transitions were predicted with the RMSD of $0.073 \mathrm{~cm}^{-1}$. Therefore, this potential for $\mathrm{Xe}-\mathrm{N}_{2} \mathrm{O}$ is not accurate enough. Recently, a three-dimensional potential has been reported by Wang et al. [22]. Based on this potential, the calculated precision has been greatly improved, but the RMSD of 152 rovibrational transitions is also more than $0.016 \mathrm{~cm}^{-1}$, which is still not accurate enough to help the spectral assignment. Besides, the infrared spectrum is just observed and analyzed in the $\mathrm{v}_{3}$ region of $\mathrm{N}_{2} \mathrm{O}$, and we can not get knowledge of different dynamical information of $\mathrm{Xe}-\mathrm{N}_{2} \mathrm{O}$ complex upon $\mathrm{v}_{1}$ vibrational excitation of $\mathrm{N}_{2} \mathrm{O}$ monomer. In fact, a section of spectrum was observed seven years ago, but just 5 rotational resolved lines are not enough to perform an effective rovibrational analysis even if the ground rotational constants were given. Here, we construct three two-dimensional PESs for the ground and excited states of 
$\mathrm{Xe}-\mathrm{N}_{2} \mathrm{O}$ complex. Based on the results of bound state calculations and the reported rotational constants [9], we make a rovibrational analysis of our observed spectrum for $\mathrm{Xe}-\mathrm{N}_{2} \mathrm{O}$ using a new method. The excellent agreement between experimental and theoretical results confirms that this new method is extremely helpful to make a rovibrational analysis for the infrared spectrum of van der Waals complex.

\section{Computational and experimental details}

\subsection{Theoretical calculations}

The potentials for $\mathrm{Xe}-\mathrm{N}_{2} \mathrm{O}$ are constructed at the rigid rotor approximation and the $\mathrm{N}-\mathrm{N}$ and $\mathrm{N}-\mathrm{O}$ bond lengths used here are listed in Table 1 for its ground and excited states of $\mathrm{N}_{2} \mathrm{O}$ monomer $[28,29]$. We obtain the bond lengths for excited states of $\mathrm{N}_{2} \mathrm{O}$ monomer by using the basic theory of a linear triatomic molecule [30]. The detailed calculation is presented in Supplementary data.

The intermolecular energy of each geometry was calculated using the supermolecular method at the level of single and double excitation coupled-cluster method with a noniterative perturbation treatment of triple excitations $[\mathrm{CCSD}(\mathrm{T})]$ [31]. The augmented correlation consistent polarized valence triple-zeta (aug-cc-pVTZ) basis sets of Woon and Dunning [32] are employed for N and O atoms, while the augmented correlation-consistent polarized valence quintuple-zeta (aug-cc-pV5Z-PP) basis set was chosen for Xe atom [33, 34]. The bond functions (3s3p2d1f1g) (for 3s and 3p, $\alpha=0.9,0.3,0.1$; for 2d, $\alpha=0.6,0.2$; for 1 f and $1 \mathrm{~g}, \alpha=0.3$ ) [35] are also used at the middle point of the intermolecular distance $R$. The full counterpoise procedure of Boys and Bernardi [36] is employed to correct the basis set superposition error (BSSE). All the calculations are carried out using the Molpro 2010 software package [37]. The ab initio potential energy grids were selected for $\mathrm{Xe}-\mathrm{N}_{2} \mathrm{O}$ with 31 the radial grids from 1.50 to $10.00 \AA$ and 13 angular grids from $0^{\circ}$ to $180^{\circ}$ in the step of $15^{\circ}$. The three two-dimensional PESs are constructed by executing two one-dimensional interpolations with the Lagrange polynomial formula, this interpolation scheme has employed in the previous study [38].

Within the rigid rotor approximation for the linear $\mathrm{N}_{2} \mathrm{O}$ molecular, the Hamiltonian of the $\mathrm{Xe}-\mathrm{N}_{2} \mathrm{O}$ complex in Jacobi coordinates can be written as [39]: 


$$
\hat{H}=-\frac{1}{2 \mu} \frac{\partial^{2}}{\partial R^{2}}+\frac{1}{2 \mu R^{2}}(\hat{J}-\hat{j})^{2}+B_{N_{2} O} \hat{j}^{2}+V(R, \theta)
$$

where $\mu$ is the reduced mass of the $\mathrm{Xe}-\mathrm{N}_{2} \mathrm{O}$ complex, $\hat{J}$ is total angular momentum and $\hat{j}$ is the angular momentum for $\mathrm{N}_{2} \mathrm{O}$ monomer, and $B_{\mathrm{N}_{2} \mathrm{O}}$ is the rotational constant of $\mathrm{N}_{2} \mathrm{O}$ with the values of $0.419011,0.417255$, and $0.415560 \mathrm{~cm}^{-1}$ in its ground and excited vibrational states of $\mathrm{N}_{2} \mathrm{O}$ monomer [28, 29]. The wave function used here was given in Ref. 38. The bound state calculation program is OpenMP parallelized and the PARPACK software package [40] is applied to solve the eigenvalues and eigenfunctions of the bound states. The rovibrational bound states were calculated with the total angular momentum up to $J_{\text {tot }}=6$ for the ground and excited states. In our calculations we used 200 sine-DVR points for the $R$ coordinate, 246 basis functions of associated Legendre polynomials, and 200 DVR grid points for $\theta$. The convergence accuracy of eigenvalues is evaluated to be better than $0.001 \mathrm{~cm}^{-1}$.

\subsection{Experiment}

The spectrometer used to record the spectrum of $\mathrm{Xe}-\mathrm{N}_{2} \mathrm{O}$ complex has been in detailed described in Ref. 13. The $\mathrm{Xe}-\mathrm{N}_{2} \mathrm{O}$ complex was formed by expanding a mixture of $0.5 \% \mathrm{~N}_{2} \mathrm{O}$ and $15 \% \mathrm{Xe}$ in the He carrier gas through two 800 -mm pin-hole nozzles at room temperature. Backing pressure was 3 atm for $\mathrm{Xe}-\mathrm{N}_{2} \mathrm{O}$. The spectrum was calibrated against the accurate line positions of $\mathrm{N}_{2} \mathrm{O}$ using a confocal etalon with a free spectral range of $0.01 \mathrm{~cm}^{-1}$. Our experimental accuracy of the measurement was estimated to be better than $0.0005 \mathrm{~cm}^{-1}$ and the spectrum is analyzed and fit using the SPFIT program [41].

\section{Results and analysis}

\subsection{Ab initio PESs and bound state calculations}

The contour plots of $V(R, \theta)$ are shown in Figure 1. The three intermolecular PESs have very similar features and each potential is characterized by a global T-shaped minimum, a linear local minima, and two saddle points located at the sides of global minimum. For the ground state, the global minimum is located at $R=3.75 \AA$ and $\theta=87.0^{\circ}$ with a depth of $283.933 \mathrm{~cm}^{-1}$. The local minimum corresponds to the linear geometry at $R=4.83 \AA, \theta=0.0^{\circ}$ with a depth well of 162.017 
$\mathrm{cm}^{-1}$. The saddle point 1 connecting the global and the local minimum is located at $R=4.69 \AA, \theta$ $=30.0^{\circ}$ with a height of only $3.518 \mathrm{~cm}^{-1}$, relative to the linear local minimum. The saddle point 2 connects the two global minima is located at $R=5.16 \AA, \theta=180.0^{\circ}$ with a height of $153.482 \mathrm{~cm}^{-1}$, relative to the nearly T-shape minimum. The geometries and energies of the minima and saddle points on the ab initio PESs are listed in Table 2 including the previous results for comparison. The previous PES for $\mathrm{Xe}-\mathrm{N}_{2} \mathrm{O}$ was performed by Chen et al. at the CCSD(T) level in 2004 [19]. As seen in Table 2, the global minimum was located at $R=3.80 \AA$ and $\theta=88.0^{\circ}$ with a depth of $256.510 \mathrm{~cm}^{-1}$ on this potential. To our knowledge, the geometry of global minimum presented in Ref. 9 is $R_{\mathrm{m}}=3.7806 \AA, \theta=82.99^{\circ}$ and $V_{\mathrm{m}}=-213.21 \mathrm{~cm}^{-1}$, indicated that both results are in good agreement with that of previous determination. For the excited states, the well depth of the global minimum and the local minimum on the potentials for both excited states are deeper than those of ground state, indicated that there is a slight strengthen of the vdW interaction upon vibrational excitation and a red shift is to occur for the infrared spectra of $\mathrm{Xe}-\mathrm{N}_{2} \mathrm{O}$ in the $v_{1}$ and $\mathrm{v}_{3}$ region of $\mathrm{N}_{2} \mathrm{O}$ monomer.

The bound energy of vibrational ground state for the T-shaped structure of $\mathrm{Xe}-\mathrm{N}_{2} \mathrm{O}$ complex is calculated to be $-246.712 \mathrm{~cm}^{-1}$, corresponding to a zero-point energy of $36.221 \mathrm{~cm}^{-1}$. For the linear structure of $\mathrm{Xe}-\mathrm{N}_{2} \mathrm{O}$, the bound energy of vibrational ground state is calculated to be $-141.863 \mathrm{~cm}^{-1}$, corresponding to a zero-point energy of $20.154 \mathrm{~cm}^{-1}$. The ground energy level is more than $15 \mathrm{~cm}^{-1}$ higher than that of the saddle point 1 , indicated that the obvious quantum delocalization effect will occur. For the two excited states, the bound energy, as well as the zero-point energy is almost equivalent to those of ground state. The bound energy of vibrational excited states for the T-shaped structure of $\mathrm{Xe}-\mathrm{N}_{2} \mathrm{O}$ complex is calculated to be -246.845 and $-246.972 \mathrm{~cm}^{-1}$ for the monomer $v_{1}$ and $v_{3}$ excited states, respectively.

The intermolecular vibrational states can be characterized by two quantum numbers $\left(n_{\mathrm{s}}, n_{\mathrm{b}}\right)$, where $n_{\mathrm{s}}$ stands for the van der Waals stretching mode and $n_{\mathrm{b}}$ is the bending mode. Here, just the intermolecular modes of ground state are calculated and discussed in this paper. The frequencies for the first twelve vibrational modes are listed in Table 3, including their vibrational assignments. These vibrational states are assigned unambiguously via the wavefunction analysis. Figure 2 is $R-\theta$ contour plots of the wavefunctions for the assigned vibrational states of $\mathrm{Xe}-\mathrm{N}_{2} \mathrm{O}$ complex. 
The ground state $(0,0)$ is localized in the T-shaped global minimum, and the second and third roots are attributed to the intermolecular stretching $(1,0)$ and bending $(0,1)$ modes with the vibrational frequencies of 33.155 and $34.021 \mathrm{~cm}^{-1}$, respectively. These results are in agreement with those presented in Chen's work. The following three vibrational modes can be assigned at the sequence of $(2,0),(0,2),(1,1)$ with the vibrational frequencies of $61.627,62.081$ and 66.770 $\mathrm{cm}^{-1}$, respectively. This sequence of vibrational modes is not consistent with those given in Ref. 19. The reason for this difference can be attributed to the factor that the vibrational frequency for the two fundamental modes is almost equivalent in our work, but the energy difference was calculated to be $3.5 \mathrm{~cm}^{-1}$ given in Ref. 19. Due to lack of experimental results, it is difficult to confirm which result is more reliable.

We also make an assignment for the linear isomer and the $R-\theta$ contour plots of the wavefunctions were presented in Figure 3. As seen in Figure 3, there is obvious delocalization effect for the ground wavefunction because the zero-point energy of the linear structure is larger than the barrier height. The following three excited vibrational modes of the linear structure are all assigned as the intermolecular stretching modes with the vibrational frequencies of 25.226, 49.561 and $66.506 \mathrm{~cm}^{-1}$, respectively.

\subsection{Infrared spectra}

The frequencies of rotational energy levels and their assignments are listed in Table S1 in the supplementary data. A section of spectrum with five lines recorded in the $v_{1}$ region of $\mathrm{N}_{2} \mathrm{O}$ monomer for $\mathrm{Xe}-\mathrm{N}_{2} \mathrm{O}$ was presented in Figure 4. The rotational constants of the ground state have been determined to be $\mathrm{A}=12769.5(5), \mathrm{B}=1075.5(2), \mathrm{C}=986.9(1) \mathrm{MHz}$ by Herrebout et al. [9]. Based on these rotational constants and bound states results, we make a rovibrational analysis of our observed spectrum. Using the data listed in Table S1, an energy difference can be obtained using the following expression

$$
\Delta E=E_{J_{K_{a}^{\prime} K_{c}^{\prime}}^{\prime}}-E_{J^{\prime \prime}{ }_{K_{a}^{\prime \prime} K_{c}^{\prime \prime}}}
$$

where all the quantum numbers $\left(J, K_{a}\right.$, and $\left.K_{c}\right)$ take the same values for the ground and excited states, namely $J^{\prime}=J^{\prime \prime}, K_{a}^{\prime}=K_{a}^{\prime \prime}$ and $K_{c}^{\prime}=K_{c}^{\prime \prime}$. A diagram is presented in Figure 5 for energy differences of the rotational energy levels with $J \leq 5$ and $K_{a} \leq 4$. As seen in Figure 5, the 
calculated deviation of energy differences can be significant reduced by above-mentioned method, so it is more reliable to make a rovibarional analysis of our observed spectrum using these energy differences with the rotational constants of ground states fixed at the values determined by Herrebout et al. [9] for $\mathrm{Xe}-\mathrm{N}_{2} \mathrm{O}$ complex. The derived rotational constants are listed in Table 4 for the excited states upon the $v_{1}$ and $v_{3}$ excitation of $\mathrm{N}_{2} \mathrm{O}$ monomer. Based on these rotational constants, the five lines presented in Figure 4 can be assigned as the $R(3)-R(7)$ of $R$-branch unambiguously. The line frequencies and their assignments are listed in Table 5, including the corresponding spectral lines of the monomer $v_{3}$ excited state. Using the line frequencies and derived rotational constants, the band origin of our observed spectrum is determined to be $1284.8760 \mathrm{~cm}^{-1}$ with a red shift of $0.0273 \mathrm{~cm}^{-1}$ compared to that of $\mathrm{N}_{2} \mathrm{O}$ monomer. Similarly, the band origin is determined to be $2223.26592 \mathrm{~cm}^{-1}$ in the $\mathrm{N}_{2} \mathrm{O}$ monomer $v_{3}$ band, which is in excellent agreement with the experimental result with a deviation of only $0.0001 \mathrm{~cm}^{-1}$. To illustrate the accuracy of our calculated method, we give a detailed calculation for the observed transitions in the $v_{3}$ region of $\mathrm{N}_{2} \mathrm{O}$ monomer. These results were listed in Table $\mathrm{S} 2$ and the RMSD of 152 rotational transitions is $0.00075 \mathrm{~cm}^{-1}$, which is very close to the value $\left(0.00049 \mathrm{~cm}^{-1}\right)$ of experimental fit. The simulated spectra of $\mathrm{Xe}-\mathrm{N}_{2} \mathrm{O}$ are also shown in Figure 4. The rotational temperature and Gaussian line-width of simulated spectra are set at $1.5 \mathrm{~K}$ and $0.004 \mathrm{~cm}^{-1}$, respectively. The simulated spectrum of $\mathrm{Xe}-\mathrm{N}_{2} \mathrm{O}$ reproduces the observed spectrum very well (see the small section shown in the box of Figure 4).

\section{Discussion and conclusions}

\subsection{Structural parameters}

The average structural parameters $\langle R\rangle$ and $\langle\theta\rangle$ for a vibrational state can be determined from the related wavefunctions using the following formulas [42]

$$
\left\langle\frac{1}{R^{2}}\right\rangle \approx \frac{1}{\left\langle R^{2}\right\rangle} \text { and } P_{2}(\cos \langle\theta\rangle)=\left\langle P_{2}(\cos \theta)\right\rangle
$$

where $P_{2}$ is the second-order Legendre function and $\left\langle P_{2}(\cos \theta)\right\rangle$ is the average value of the Legendre function for the state of interest. The calculated structural parameters of the ground and excited states for $\mathrm{Xe}-\mathrm{N}_{2} \mathrm{O}$ complex are listed in Table 6. As seen in the Table 6, the average 
structural parameter for the intermolecular distance $R$ of $\mathrm{Xe}-\mathrm{N}_{2} \mathrm{O}$ complex is calculated to be $3.809 \AA$ in the case of T-shaped isomer, which is in good agreement with the experimental determination with a difference of $0.021 \AA$. The corresponding rotational angle $\theta$ was determined to be $82.94^{\circ}$, which just has a deviation of $0.05^{\circ}$. For the excited states, both the calculated values and variable trend for these parameters are also in good agreement with the experimental results. In the case of linear isomer, the intermolecular distance is calculated to be $4.62 \AA$ and the corresponding angle is $32.89^{\circ}$. However, there is obvious delocalization effect existing at the radial and angular directions for the linear isomer, we think that these parameters can not be calculated accurately.

It is very interesting to compare the structural parameters between local minima on the PES and the vibrationally average values. For the intermolecular distance, the deviation between the average value and the equilibrium structure is quite small, which is about $0.05 \AA$ for the three vibrational states. For the rotational angles, there are great deviations between the average and equilibrium structure, and the values are about $4.0^{\circ}$ for the three vibrational states. The larger deviations of $\langle\theta\rangle$ from their equilibrium values can be thought of as an effect of librational motion of $\mathrm{N}_{2} \mathrm{O}$ monomer in the complex.

\subsection{Vibrational shifts}

As seen in Table S1, there are red shifts of 0.133 and $0.260 \mathrm{~cm}^{-1}$ upon the $v_{1}$ and $v_{3}$ vibrational excitation of $\mathrm{N}_{2} \mathrm{O}$, respectively. Compared with the experimental value of 0.0273 and $0.491 \mathrm{~cm}^{-1}$ in the $v_{1}$ and $v_{3}$ region of $\mathrm{N}_{2} \mathrm{O}$, our predicted vibrational shifts are in qualitative agreement with the experimental observation. To our knowledge, the band origin shifts for $\mathrm{Rg}-\mathrm{N}_{2} \mathrm{O}(\mathrm{Rg}=\mathrm{Ne}, \mathrm{Ar}, \mathrm{Kr}$, and $\mathrm{Xe})$ have been well explained using a simple model based on the Buckingham potential by Herrebout et al. [9]. Our previous work has proved that this model is also suitable to the $\mathrm{Rg}-\mathrm{N}_{2} \mathrm{O}$ complexes $(\mathrm{Rg}=\mathrm{Ne}, \mathrm{Ar}$, and $\mathrm{Kr})$ in the $v_{1}$ region of $\mathrm{N}_{2} \mathrm{O}$ monomer. Here we will examine whether this model can be applicable to $\mathrm{Xe}-\mathrm{N}_{2} \mathrm{O}$ in this spectral region. These results are presented in Figure 6. As seen in Figure 6, the plot of $\Delta v /\left(C_{6} / R_{m}^{6}\right)$ versus $3 \beta /$ $R_{\mathrm{m}}$ for $\mathrm{Rg}-\mathrm{N}_{2} \mathrm{O}(\mathrm{Rg}=\mathrm{Ne}, \mathrm{Ar}, \mathrm{Kr}$ and $\mathrm{Xe})$ also makes a linear relationship in the $v_{1}$ region of $\mathrm{N}_{2} \mathrm{O}$ monomer. The intercept is $\Delta C_{6} / C_{6}=0.00487$ and the slope is $\left\langle\Delta q^{2}\right\rangle=0.00167$, while the corresponding values in the $v_{3}$ region of $\mathrm{N}_{2} \mathrm{O}$ [9] are 0.00119 and 0.0037 , respectively. In our 
previous work [15], the band origin shift of $\mathrm{Xe}-\mathrm{N}_{2} \mathrm{O}$ in the $v_{1}$ region of $\mathrm{N}_{2} \mathrm{O}$ was predicted to be $-0.0333 \mathrm{~cm}^{-1}$ by extrapolation from the plot for $\mathrm{Rg}-\mathrm{N}_{2} \mathrm{O}(\mathrm{Rg}=\mathrm{Ne}, \mathrm{Ar}$ and $\mathrm{Kr})$. This result reproduces our observed result with good accuracy, indicated that the simple mode based on the Buckingham potential can give a precise prediction of vibrational shifts for $\mathrm{Rg}-\mathrm{N}_{2} \mathrm{O}$ complexes $(\mathrm{Rg}=\mathrm{Ne}, \mathrm{Ar}, \mathrm{Kr}$ and $\mathrm{Xe})$.

In conclusion, a new theoretical and experimental study of the potential energy surface, bound states, and infrared spectrum are performed for $\mathrm{Xe}-\mathrm{N}_{2} \mathrm{O}$ complex. Three two-dimensional PESs are constructed for $\mathrm{Xe}-\mathrm{N}_{2} \mathrm{O}$ complex at the $\mathrm{CCSD}(\mathrm{T})$ level supplemented with bond functions. Intermolecular vibrational states for both T-shaped and linear isomers are assigned from the analysis of their wavefunctions. The wavefunction of linear isomer undergoes obvious quantum delocalization effect, indicated the spectrum of linear isomer can not be observed in experiment. The band origins for both excited states are predicted to be red shift with the values of 0.133 and $0.260 \mathrm{~cm}^{-1}$ in the monomer $v_{1}$ and $v_{3}$ region, respectively. Compared with the experimental values, our predicted vibrational shifts are in at least qualitative agreement with the experimental observations.

A section of infrared spectrum (including 5 rotational resolved lines) for $\mathrm{Xe}-\mathrm{N}_{2} \mathrm{O}$ has been recorded in the $\mathrm{N}_{2} \mathrm{O}$ monomer $v_{1}$ region using an infrared tunable diode laser spectrometer in conjunction with a free supersonic jet expansion. A new method is developed to make a rovibrational analysis of our observed spectrum for $\mathrm{Xe}-\mathrm{N}_{2} \mathrm{O}$. The rotational constants for the excited state are derived with the values of $\mathrm{A}=12716.1, \mathrm{~B}=1075.2, \mathrm{C}=987.9 \mathrm{MHz}$ and the band origin of the spectrum is determined to be $1284.8760 \mathrm{~cm}^{-1}$ with a red shift of $0.0273 \mathrm{~cm}^{-1}$ compared to that of $\mathrm{N}_{2} \mathrm{O}$ monomer in the $v_{1}$ region. The excellent agreement between experimental and theoretical results confirms that this new method is extremely helpful to make a rovibrational analysis for the infrared spectrum of van der Waals complex.

\section{Acknowledgments}

This work was supported by the National Science Foundation of China (Project Nos. 11304095). The authors thank Prof. Chuanxi Duan for providing the site to finish the experiment and also thank Prof. Minghui Yang for giving lots of helpful suggestions.

\section{Reference:}


[1] See http://en.wikipedia.org/wiki/Nitrous_oxide for the introduction of Nitrous oxide.

[2] S. E. Novick, Bibliography of rotational spectra of weakly bound complexes; Electronic updates are available on the web at https://wesfiles.wesleyan.edu/home/snovick/SN_webpage/ vdw.pdf, 2015.

[3] C. H. Joyner, T. A. Dixon, F. A. Baiocchi, W. Klemperer, J. Chem. Phys. 75 (1981) 5285-5290.

[4] H. O. Leung, D. Gangwani, J.-U. Grabow, J. Mol. Spectrosc. 184 (1997) 106-112.

[5] M. S. Ngari, W. Jäger, J. Mol. Spectrosc. 192 (1998) 452-454.

[6] H. Hodge, G. D. Hayman, T. R. Dyke, B. J. Howard, J. Chem. Soc. Faraday Trans. 82 (1986) 1137-1142.

[7] T. A. Hu, E. L. Chappell, S. W. Sharpe, J. Chem. Phys. 98 (1993) 6162-6169.

[8] G. Gimmler, M. Havenith, J. Mol. Struct. 599 (2001) 117-123.

[9] W. A. Herrebout, H.-B. Qian, H. Yamaguchi, B. J. Howard, J. Mol. Spectrosc. 189 (1998) 235-243.

[10] M. S. Ngari, W. Jäger, J. Mol. Spectrosc. 192 (1998) 320-330.

[11] J. Tang, A. R. W. McKellar, J. Chem. Phys. 117 (2002) 2586-2591.

[12] X. G. Song, Y. J. Xu, P.-N. Roy, W. Jäger, J. Chem. Phys. 121 (2004) 12308-12314.

[13] D. S. Zhu, R. B. Wang, R. Zheng, G. M. Huang, C. X. Duan, J. Mol. Spectrosc. 253 (2009) $88-91$.

[14] R. Zheng, D. S. Zhu, Y. Zhu, C. X. Duan, J. Mol. Spectrosc. 263 (2010) 174-177.

[15] R. Zheng, Y. Zhu, S. Li, C. X. Duan, Mol. Phys. 109 (2011) 823-830.

[16] H. Zhu, D. Q. Xie, G. S. Yan, Chem. Phys. Lett. 351 (2002) 149-157.

[17] H. Zhu, D.Q. Xie, G. S. Yan, J. Comput. Chem. 24 (2003) 1839-1845.

[18] R. Chen and H. Zhu, J. Theo. Comput. Chem. 7 (2008) 1093-1102.

[19] J. X. Chen, H. Zhu, D. Q. Xie and G. S. Yan, Acta Chimica Sinica 62 (2004) 5-9.

[20] J. H. Wang, Y. L. Han, Z. Li, E. Y. Feng, W. Y. Huang, Mol. Phys. 111 (2013) 771-777.

[21] Z. Wang, E. Feng, C. Zhang, C. Sun, Chem. Phys. Lett. 626 (2015) 43-48.

[22] Z. Wang, E. Feng, C. Zhang, C. Sun, Chem. Phys. Lett. 638 (2015) 66-71.

[23] B.T. Chang, O. Akin-Ojo, R. Bukowski, K. Szalewicz, J. Chem. Phys. 119 (2003) 11654-11670.

[24] Y. Z. Zhou, D. Q. Xie, J. Chem. Phys. 120 (2004) 8575-8581.

[25] Y. Z. Zhou, D. Q. Xie, D. H. Zhang, J. Chem. Phys. 124 (2006) 143317.

[26] L. C. Wang, D. Q. Xie, H. Guo, H. Li, R. J. Le Roy, P. N. Roy, J. Mol. Spectrosc. 267 (2011) 136-143.

[27] L. C. Wang, D. Q. Xie, R. J. Le Roy, P. N. Roy, J. Chem. Phys. 137 (2012) 104311.

[28] J.-L. Teffo, A. Chedin, J. Mol. Spectrosc. 135 (1989) 389-409.

[29] A. G. Maki, and J. S. Wells, Wavenumber calibration tables from heterodyne frequency measurements, NIST Special Publication 821, 1991.

[30] G. H. Herzberg, Infrared and Raman Spectra of Polyatomic Molecules, Van Nostrand 
Reinhold, New York, 1945.

[31] C. Hampel, K. Peterson, and H. J.Werner, Chem. Phys. Lett. 190 (1992) 1-12.

[32] D. E. Woon and T. H. Dunning, J. Chem. Phys. 98 (1993) 1358-1371.

[33] K. A. Peterson, D. Figgen, E. Goll, H. Stoll, and M. Dolg, J. Chem. Phys. 119 (2003) 11113.

[34] Q. Wen and W. Jäger, J. Chem. Phys. 122 (2005) 214310.

[35] T. B. Pedersen, B. Fernandez, H. Koch, and J. Makarewicz, J. Chem. Phys. 115 (2001) 8431.

[36] S. F. Boys and F. Bernardi, Mol. Phys. 19 (1970) 553-566.

[37] H. J. Werner, P. J. Knowles, G. Knizia, F. R. Manby, M. Schütz et al., MOLPRO, version 2010.1, a package of ab initio programs, 2010, see http://www.molpro.net.

[38] L. M. Zang, W. Dai, L. M. Zheng, C. X. Duan, Y. P. Lu, and M. H. Yang, J. Chem. Phys. 140 (2014) 114310.

[39] S. Y. Lin and H. Guo, J. Chem. Phys. 117 (2002) 5183-5191.

[40] R. Lehoucq, D. C. Sorensen, and C. Yang, ARPACK User's Guide: Solution of Large-Scale Eigenvalue Problems with Implicitly Restarted Arnoldi Methods, SIAM, Philadelphia, PA, 1998 (http://www.caam.rice.edu/software/ARPACK).

[41] H. M. Pickett, J. Mol. Spectrosc. 148 (1991) 371-377.

[42] L. A. Lajohm, P. A. Christiansen, R. B. Ross, T. Atashroo, W. C. Ermler, J.Chem.Phys. 87 (1987) 2812-2824.

[43] J. Zhu, Y.-P. Lu, X.-R. Chen, and Y. Cheng, Eur. Phys. J. D, 33 (2005) 43-48.

\section{Figure Captions:}

Figure 1 Contour plots of the intermolecular potential energy surface for the ground and excited states of Xe- $\mathrm{N}_{2} \mathrm{O}$ complex, $\mathrm{R}$ in angstrom and $\theta$ in degree. (a) the PES of ground state, (b) the PES of excited state for monomer $v_{1}$ mode, $(c)$ the PES of excited state for monomer $v_{3}$ mode.

Figure 2 The $R$ - $\theta$ contour plots of the wavefunctions for the T-shaped isomer for ground state.

Figure 3 The $R-\theta$ contour plots of the wavefunctions for the linear isomer for ground state.

Figure 4 Observed (upper) and simulated (lower) spectra of $\mathrm{Xe}-\mathrm{N}_{2} \mathrm{O}$ complex in the $v_{1}$ region of $\mathrm{N}_{2} \mathrm{O}$. The rotational temperature of $1.5 \mathrm{~K}$ and a Gaussian line-width of $0.004 \mathrm{~cm}^{-1}$. The line labeled with asterisk belongs to the $\mathrm{N}_{2} \mathrm{O}$ monomer.

Figure 5 The energy differences for the ground and excited states between experiment and theoretical calculation based on PES I and PES III, G.L. stands for the energy of ground state and E.L. is the energy level of $v_{3}$ monomer excited state in the figure.

Figure 6 Relationship between $\left[\Delta v /\left(\mathrm{C}_{6} / \mathrm{R}_{\mathrm{m}}^{6}\right)\right]$ and $\left(3 \beta / R_{\mathrm{m}}\right)$ for the complexes $\mathrm{Rg}-\mathrm{N}_{2} \mathrm{O}(\mathrm{Rg}=$ $\mathrm{Ne}, \mathrm{Ar}, \mathrm{Kr}$, and $\mathrm{Xe}$ ) from a model based on the Buckingham intermolecular potential. 
Table 1 The bond lengths (in $\AA$ ) of $\mathrm{N}_{2} \mathrm{O}$ used to construct the potentials.

\begin{tabular}{|c|c|c|c|}
\hline Parameters & Ground state & Monomer $v_{1}$ excited state & Monomer $v_{3}$ excited state \\
\hline$r_{\mathrm{e}}(\mathrm{N}-\mathrm{O})$ & 1.1273 & 1.1297 & 1.1319 \\
\hline$r_{\mathrm{e}}(\mathrm{N}-\mathrm{N})$ & 1.1851 & 1.1876 & 1.1900 \\
\hline
\end{tabular}

Table 2 The important geometries and corresponding energy on the potential energy surfaces $(R$ in angstrom, angles in degree and energy in $\mathrm{cm}^{-1}$ ).

\begin{tabular}{|c|c|c|c|c|}
\hline $\begin{array}{c}\text { Vibrational } \\
\text { state }\end{array}$ & Ground state & Monomer $v_{1}$ state & Monomer $v_{3}$ state & Ref. 19 \\
\hline $\begin{array}{c}\text { Global } \\
\text { minimum }\end{array}$ & $(3.75,87.0,-283.933)$ & $(3.75,87.0,-284.008)$ & $(3.75,87.0,-284.078)$ & $(3.80,88.0,-256.510)$ \\
\hline $\begin{array}{c}\text { Local } \\
\text { minimum }\end{array}$ & $(4.83,0.0,-162.017)$ & $(4.83,0.0,-162.538)$ & $(4.83,0.0,-163.046)$ & $(4.95,0.0,-107.570)$ \\
\hline $\begin{array}{c}\text { Saddle } \\
\text { point } 1\end{array}$ & $(4.69,30.0,-158.499)$ & $(4.68,31.0,-158.899)$ & $(4.68,31.0,-159.288)$ & $(4.84,27.6,-102.750)$ \\
\hline $\begin{array}{c}\text { Saddle } \\
\text { point } 2\end{array}$ & $(5.16,180.0,-130.451)$ & $(5.17,180.0,-130.582)$ & $(5.17,180.0,-130.718)$ & - \\
\hline
\end{tabular}

Table 3 The intermolecular vibratonal energy levels ( in $\mathrm{cm}^{-1}$ ) and their assignments $\left(n_{\mathrm{s}}, n_{\mathrm{b}}\right)$ for $\mathrm{Xe}-\mathrm{N}_{2} \mathrm{O}$ complex.

\begin{tabular}{|c|c|c|c|c|c|}
\hline \multicolumn{2}{|c|}{ This work } & \multicolumn{3}{c|}{ Ref. 19 } \\
\hline Assignment & Energy & Frequency & Assignment & Energy & Frequency \\
\hline Nearly T-shape isomer & -246.712 & 0.00 & $(0,0)$ & -219.94 & 0.00 \\
\hline$(0,0)$ & -213.598 & 33.115 & $(1,0)$ & -188.78 & 31.16 \\
\hline$(1,0)$ & -212.691 & 34.021 & $(0,1)$ & -184.31 & 35.63 \\
\hline$(0,1)$ & -185.085 & 61.627 & $(2,0)$ & -160.96 & 58.98 \\
\hline$(2,0)$ & -184.632 & 62.081 & $(1,1)$ & -156.72 & 63.22 \\
\hline$(0,2)$ & -179.942 & 66.770 & $(0,2)$ & -151.10 & 68.84 \\
\hline$(1,1)$ & -162.220 & 84.492 & $(3,0)$ & -136.93 & 83.01 \\
\hline$(3,0)$ & -161.552 & 85.160 & $(2,1)$ & -131.69 & 88.25 \\
\hline$(0,3)$ & -153.058 & 93.655 & $(1,2)$ & -127.44 & 92.50 \\
\hline$(2,1)$ & -151.293 & 95.419 & $(0,3)$ & -120.85 & 99.09 \\
\hline$(1,2)$ & -145.675 & 101.038 & $(0,4)$ & -116.77 & 103.17 \\
\hline$(0,4)$ & -144.588 & 102.124 & $(4,0)$ & -109.81 & 110.13 \\
\hline$(4,0)$ & -141.863 & 0.00 & & & \\
\hline Linear isomer & -116.637 & 25.226 & & & \\
\hline$(0,0)$ & -92.302 & 49.561 & 66.506 & & \\
\hline
\end{tabular}

Table 4 The determined spectroscopy parameters for $\mathrm{Xe}-\mathrm{N}_{2} \mathrm{O}$ complex.

\begin{tabular}{|c|c|c|c|c|}
\hline \multirow{2}{*}{ Parameters } & \multicolumn{2}{|c|}{ Experiment $^{\mathrm{a}}$} & \multicolumn{2}{c|}{ This work } \\
\cline { 2 - 5 } & Ground state & ${\text { Monomer } v_{3} \text { state }}$ & Monomer $v_{1}$ state & Monomer $v_{3}$ state \\
\hline $\mathrm{A} / \mathrm{MHz}$ & $12769.5(5)$ & $12663.8(3)$ & 12716.1 & 12664.5 \\
\hline $\mathrm{B} / \mathrm{MHz}$ & $1075.5(2)$ & $1075.0(2)$ & 1075.22 & 1074.96 \\
\hline $\mathrm{C} / \mathrm{MHz}$ & $988.4(1)$ & $986.9(1)$ & 987.85 & 987.31 \\
\hline $\mathrm{v} / \mathrm{cm}^{-1}$ & - & $2223.22603(9)$ & $1284.87591^{b}$ & $2223.26592^{c}$ \\
\hline
\end{tabular}

${ }^{a}$ These values given in Ref. 9 .

${ }^{b}$ The band origin of $v_{1}$ excited state is derived from our observed spectral lines.

${ }^{c}$ This value is derived from the transition frequencies of $4_{14}-3_{03}, 5_{15}-4_{04}$, and $6_{16}-5_{05}$ given in Ref. 9 . 
Table 5 Observed and Calculated transition frequencies (in $\mathrm{cm}^{-1}$ ) for $\mathrm{Xe}-\mathrm{N}_{2} \mathrm{O}$ in the $\mathrm{N}_{2} \mathrm{O}$ monomer $v_{1}$ and $v_{3}$ region

\begin{tabular}{|c|c|c|c|c|c|c|c|c|c|}
\hline \multicolumn{3}{|c|}{ Excited state } & \multicolumn{3}{c|}{ Ground state } & \multicolumn{2}{c|}{$\mathrm{N}_{2} \mathrm{O}$ monomer $v_{1}$ region } & \multicolumn{2}{c|}{$\mathrm{N}_{2} \mathrm{O}$ monomer $v_{3}$ region } \\
\hline$J$ & $K_{a}$ & $K_{c}$ & $J$ & $K_{a}$ & $K_{c}$ & Frequencies & $\Delta v$ (Obs.-Calc. $)$ & Frequencies ${ }^{a}$ & $\Delta v($ Obs.-Calc. $)$ \\
\hline 4 & 1 & 4 & 3 & 0 & 3 & 1285.52664 & 0.00029 & 2223.91455 & 0.00035 \\
\hline 5 & 1 & 5 & 4 & 0 & 4 & 1285.58774 & -0.00014 & 2223.97548 & -0.00002 \\
\hline 6 & 1 & 6 & 5 & 0 & 5 & 1285.64781 & -0.00017 & 2224.03523 & -0.00016 \\
\hline 7 & 1 & 7 & 6 & 0 & 6 & 1285.70714 & 0.00035 & 2224.09373 & -0.00018 \\
\hline 8 & 1 & 8 & 7 & 0 & 7 & 1285.76412 & -0.00023 & 2224.15090 & -0.00024 \\
\hline
\end{tabular}

${ }^{a}$ These values given in Ref. 9 .

Table 6 The structural parameters for $\mathrm{Xe}-\mathrm{N}_{2} \mathrm{O}$ complex.

\begin{tabular}{|c|c|c|c|c|}
\hline \multirow{2}{*}{ Vibrational state } & \multicolumn{2}{|c|}{ Experiment $^{a}$} & \multicolumn{2}{c|}{ This work } \\
\cline { 2 - 5 } & $R(\AA)$ & $\theta($ degree $)$ & $R(\AA)$ & $\theta($ degree $)$ \\
\hline Ground state & 3.7806 & 82.99 & 3.8090 & 82.94 \\
\hline Monomer $v_{1}$ region & - & - & 3.8095 & 82.94 \\
\hline Monomer $v_{3}$ region & 3.7824 & 83.00 & 3.8100 & 82.94 \\
\hline
\end{tabular}

${ }^{a}$ These values given in Ref. 9. 


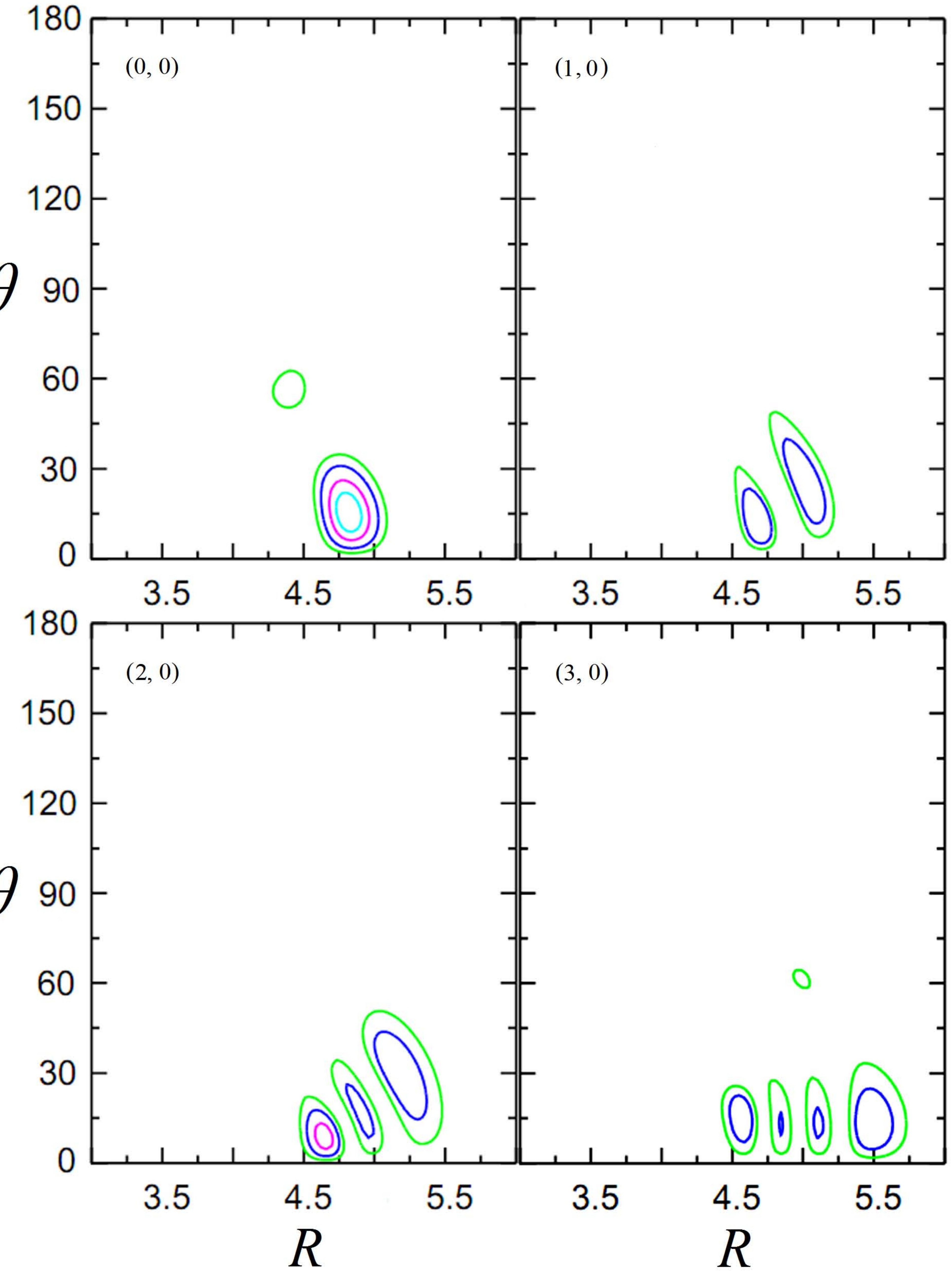




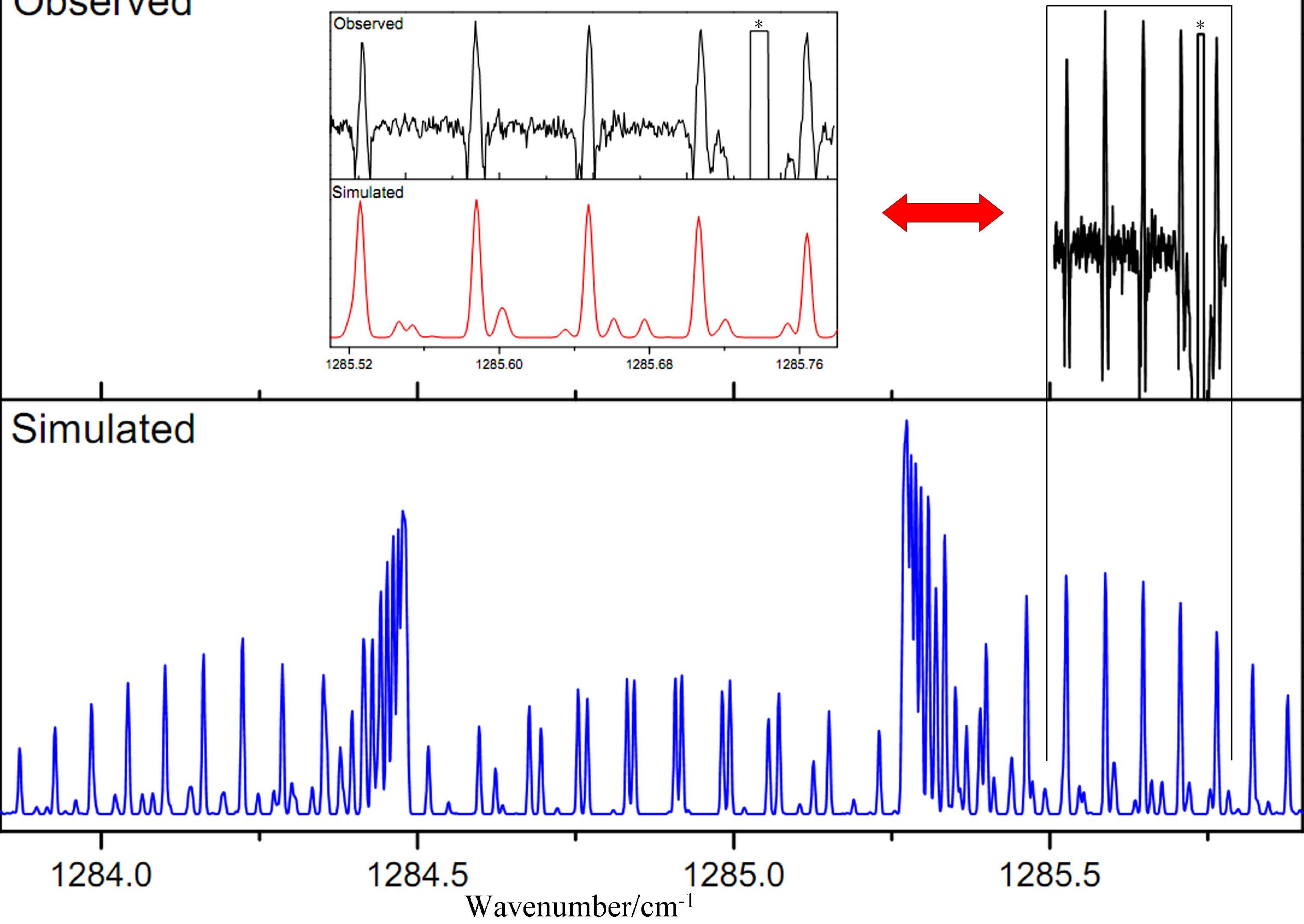




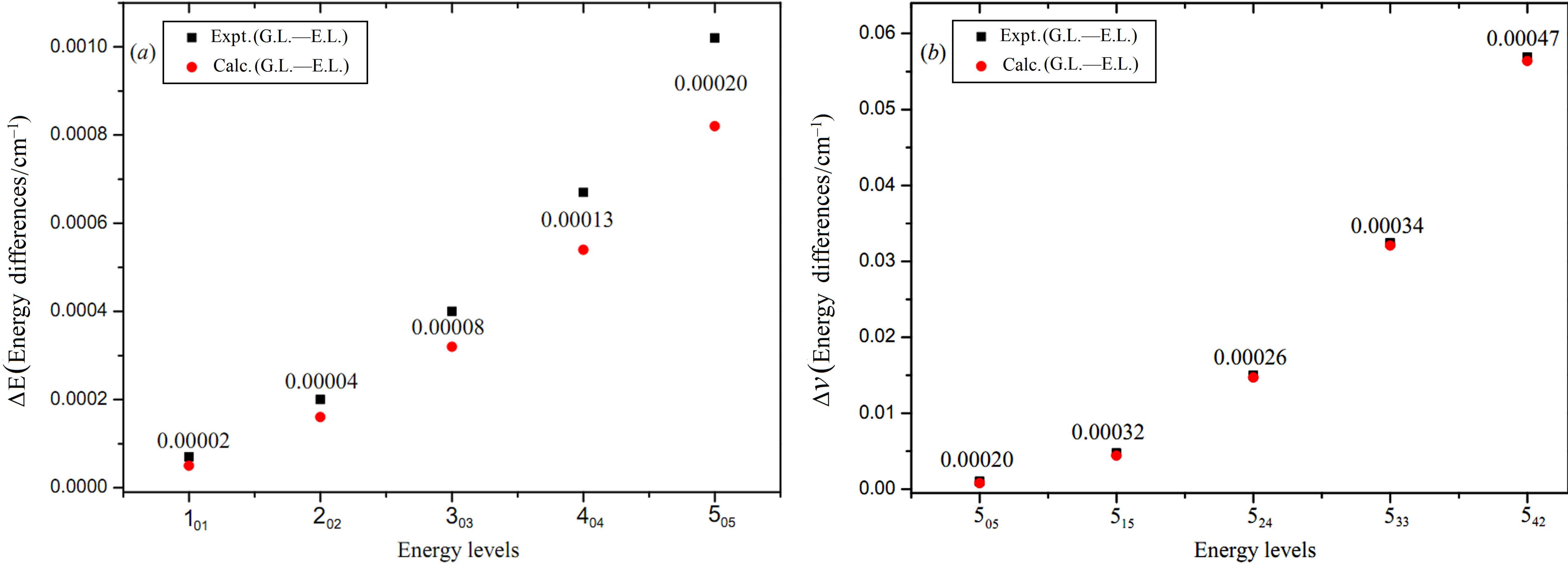




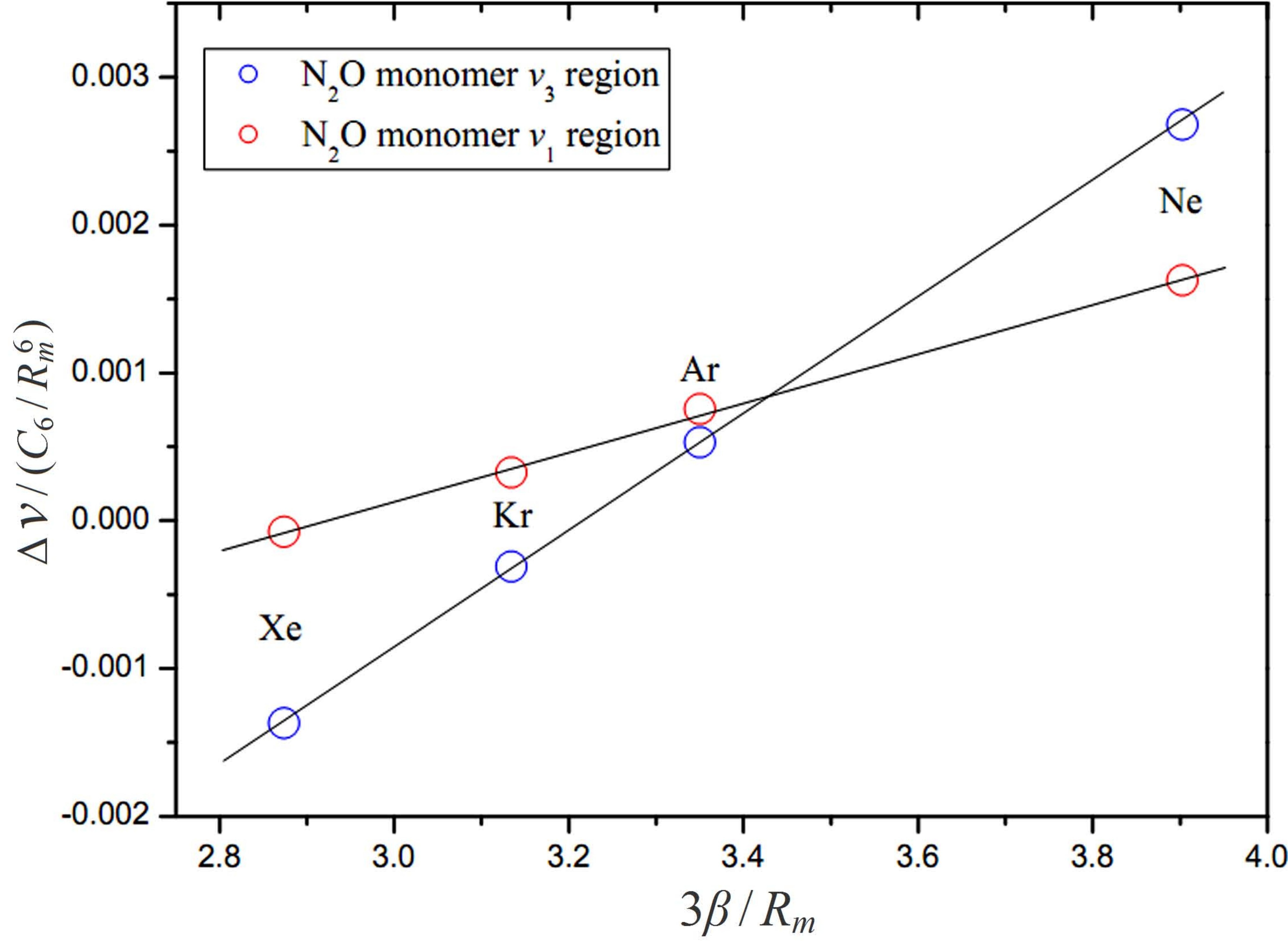




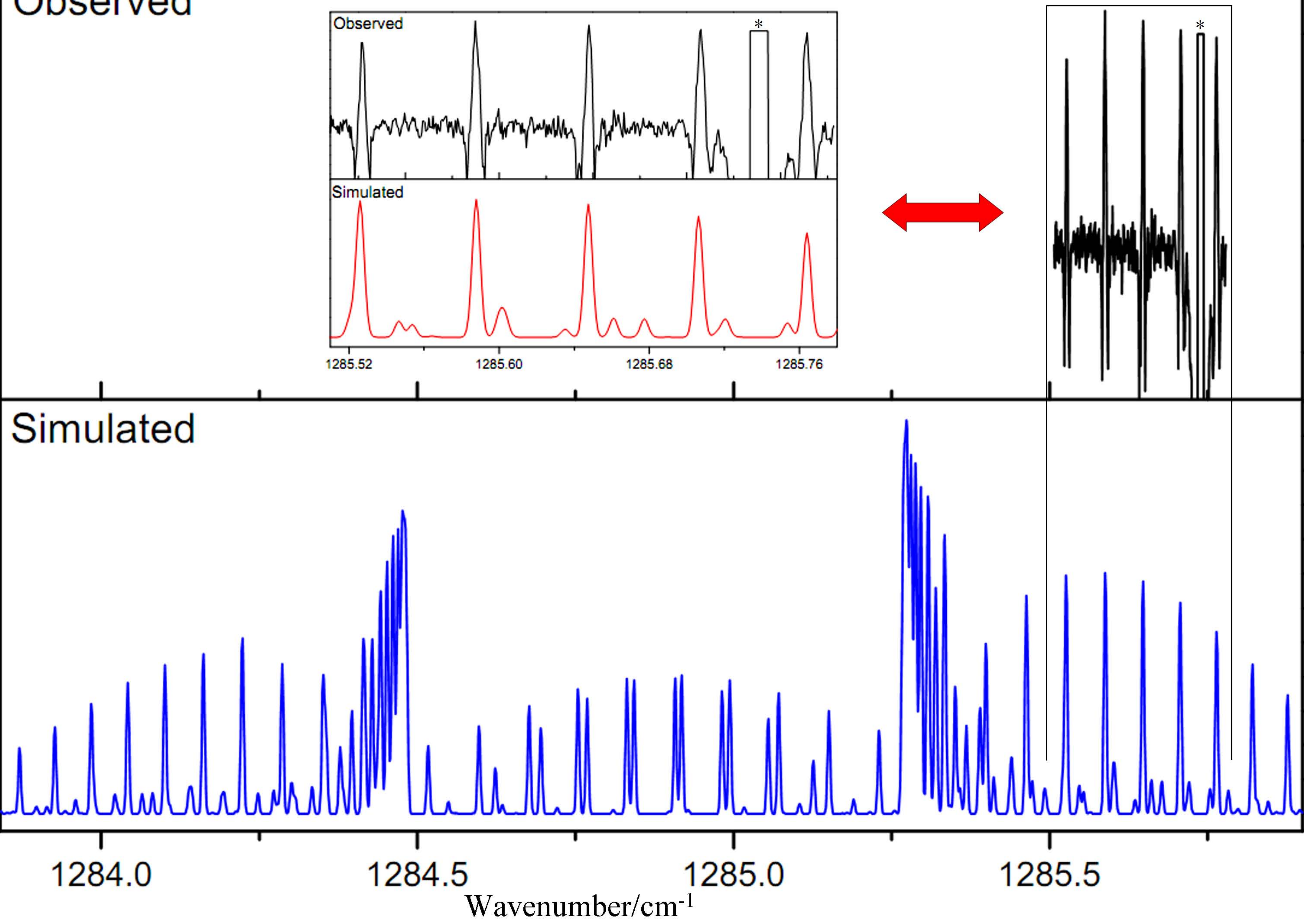

